\title{
Compute functional analysis leveraging the IAAS private cloud computing service model in packstack development
}

\author{
Mohamad Iqbal Suriansyah a, 1, ${ }^{*}$; Iyan Mulyana a, ${ }^{\text {; }}$ Junaidy Budi Sanger ${ }^{\text {b, }}$; Sandi Winata ${ }^{\text {a, } 3}$ \\ ${ }^{a}$ Computer Science Study Program FMIPA Universitas Pakuan, Indonesia \\ ${ }^{b}$ Informatics Engineering Study Program, Fakulty of Engineering Unika De La Salle Manado, Indonesia \\ ${ }^{I}$ mohamad.iqbal@unpak.ac.id; ${ }^{2}$ jsanger@unikadelasalle.ac.id; ${ }^{3}$ winatasandi05@gmail.com \\ * Corresponding author
}

Article history: Received December 3, 2020; Revised April 20, 2021; Accepted April 20, 2021; Available online April 30, 2021

\begin{abstract}
Analyzing compute functions by utilizing the IAAS model for private cloud computing services in packstack development is one of the large-scale data storage solutions. Problems that often occur when implementing various applications are the increased need for server resources, the monitoring process, performance efficiency, time constraints in building servers and upgrading hardware These problems have an impact on long server downtime. The development of private cloud computing technology could become a solution to the problem. This research employed openstack and packstack by applying one server controller node and two servers compute nodes. Server administration with IAAS and self-service approaches made scalability testing simpler and time efficient. The resizing of the virtual server (instance) that has been carried out in a running condition shows that the measurement of the overhead value in private cloud computing is more optimal with a downtime of 16 seconds.
\end{abstract}

Keywords: Private Cloud; Openstack; Packstack; Overhead; IAAS Service

\section{Introduction}

On-premises server storage that is run by a server in a data center will be very difficult if a fairly complex server is developed. This means that when doing server development, officers need to come directly to the data center. Of course, this will require more time and operational costs to develop a server. The development of server technology currently allows a server to be run on a computer network and internet storage known as cloud computing. This enables server administrators to easily develop servers because they can be accessed using the internet. Openstack is an open source for building private cloud computing services. Openstack technology has several main services, namely nova compute, neutron, swift, glance, keystone and cinder [1][2].

Cloud computing is an advanced development for the management of a resource. Currently, the development of cloud computing is very fast. This is because customers do not need to think about maintenance, scalability, and security issues from the server. Instead, the customers get full access to the server's resources. The service from the Cloud is divided into 3 parts, namely Software as a Service, Platform as a Service, and Infrastructure as a Service [3][4][5]. Target users from personal/individual to company/organization can use these services flexibly at an affordable cost as a solution for saving infrastructure costs in business development [6][7][8]. There is another definition of cloud computing, which is a new paradigm with high system performance for computing that offers easy access and specific configurations [9][10].

Several studies that have developed private cloud computing include in the first study [11] Private Cloud Computing was created and conducted an analysis of DoS implemented in schools so that it was easier for users to collect school learning data. In the second study [12] has succeeded in designing and analyzing the performance of Private Cloud Computing with the implementation of Infrastructure as a Service. In the third study [13] has performed a comparative analysis for the performance of openstack and cloudstack in the service model Infrastructure as a Service. In the fourth study [14] has implemented Private Cloud Computing as an Infrastructure as a Service. The research uses openstack.

Based on the background and several related studies that have been mentioned above, in this study we developed an optimization of server resources using openstack with the IAAS service model on private cloud computing. With a private cloud developed using OpenStack to facilitate the integration of multi-compute nodes in the private cloud, it is expected to provide greater resources to support instances that will be used by applications. 


\section{Method}

The method applied in this research is Network Development Life Cycle (NDLC) shown in Figure 1.

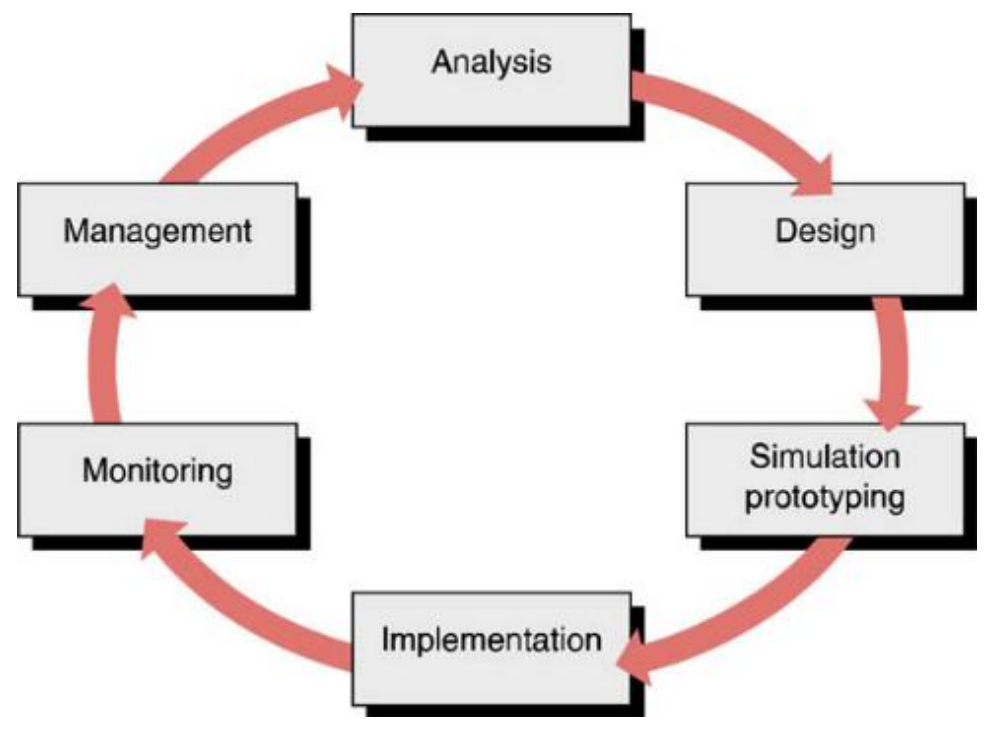

\section{A. Analysis}

Figure 1. NDLC [15].

The analysis phase was carried out by identifying the on-premises server infrastructure and finding out related existing problems. By understanding the problem, the researchers attempted to figure out why the problem occurred and how to overcome the problems. We then obtained the following data.

Table 1. Server Application Analysis

\begin{tabular}{|l|l|l|}
\hline \multirow{3}{*}{ Server } & \multicolumn{2}{|l|}{ Environment Server } \\
\cline { 2 - 3 } & $\begin{array}{l}\text { Application } \\
\text { system }\end{array}$ & Application Requirement \\
\hline \multirow{4}{*}{ Server 1 } & Application 1 & Apache2, PHP7.2, Laravel Framework \\
\cline { 2 - 3 } & Application 2 & Nginx, PHP5.6, YII Framework \\
\cline { 2 - 3 } & Application 3 & $\begin{array}{l}\text { Apache2, PHP 5.3, CodeIgniter } \\
\text { Framework }\end{array}$ \\
\hline \multirow{4}{*}{ Server 2 } & Application 4 & $\begin{array}{l}\text { Apache2, PHP 5.6, CodeIgniter } \\
\text { Framework }\end{array}$ \\
\cline { 2 - 3 } & Application 5 & Apache2, PHP7.2, Laravel Framework \\
\cline { 2 - 3 } & Application 6 & Apache2, PHP7.2, Laravel Framework \\
\hline \multirow{5}{*}{ Server 3 } & Application 7 & Apache2, PHP 5.3, CodeIgniter \\
& Application 8 & Framework \\
\cline { 2 - 3 } & Application 9 & Apache2, PHP7.2, Laravel Framework \\
\cline { 2 - 3 } & &
\end{tabular}

There were several obstacles in the process of making the server on Table 1, including 1) Making a server for 1 application took a relatively long time (around 4 hours). 2) In 1 server we could not run more than one version of PHP programming. 3) In 1 server we could not run more than one version of the web server. 4) In 1 server there could not be the same user. 5) Servers could be upgraded at any time without long downtime.

Private cloud computing was made using 3 server nodes, namely 1 controller node and 2 compute nodes. The private cloud computing was created using the IAAS service model so that an analysis of the compute function could be carried out on the compute node and resulted in the optimization of overhead from the IAAS private cloud computing model service. The illustration of Server Private Cloud is shown in Figure 2. 


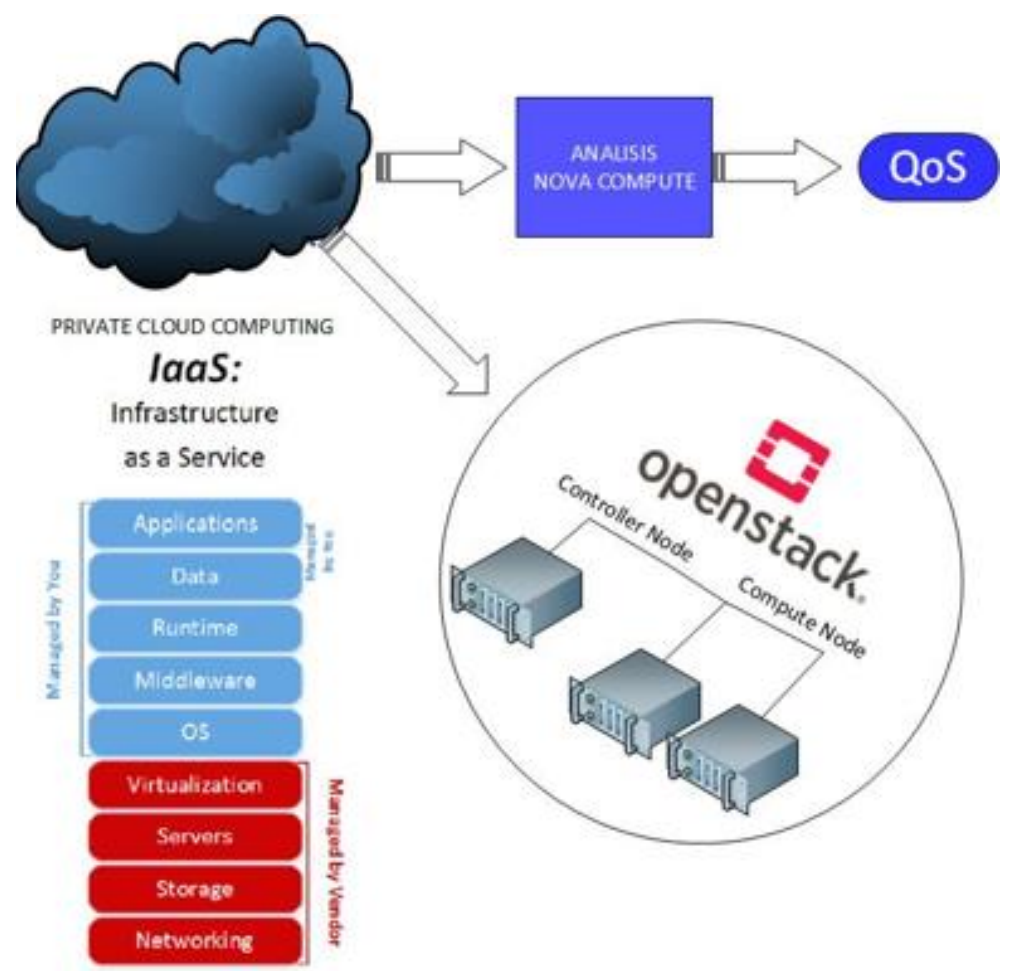

Figure 2. The illustration of Server Private Cloud

\section{B. Private Cloud Design}

The stages of system design were carried out through 3 (three) stages:

1. Private Cloud Topology Design

The design of a private cloud topology in a private cloud topology design was done using topology illustrations including IP address addressing, gateway, prefix subnetting, node controller layout and compute.

2. General system design in this research was done using the private cloud including the functions and authority of the private cloud as well as the flow connection private cloud

3. Detailed System Design

We created a list of openstack services that were needed to perform a private cloud infrastructure. System Design is shown in Figure 3.

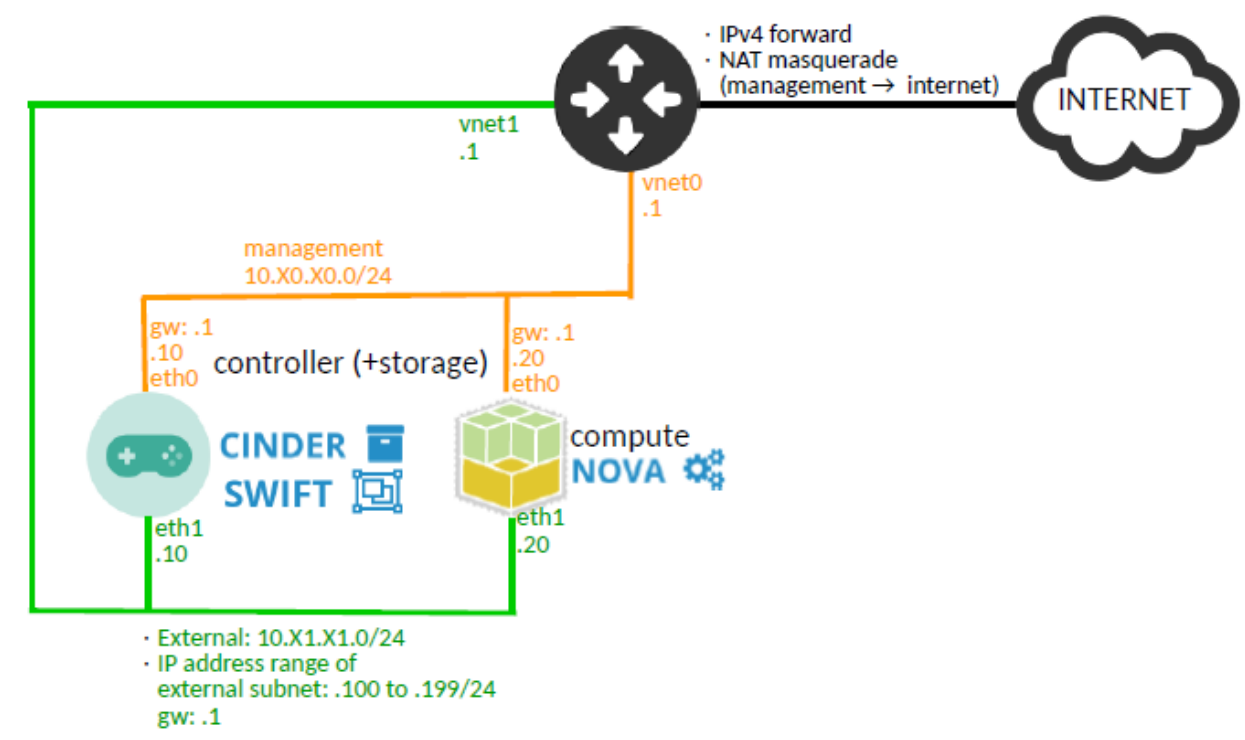

Figure 3. System Design

\section{Prototype Simulation}

At this stage, a prototype simulation was carried out using the VMware workstation application.

Suriansyah, $\boldsymbol{e t}$. al. (Compute functional analysis leveraging the IAAS private cloud computing service model in packstack development) 


\section{Implementation}

At this phase, the implementation of the results of the simulation experiments was carried out. It started from server hardware preparation, network cabling, operating system installation on the server and packstack development configuration for compute function analysis with the IAAS service model on private cloud computing based on the previous private cloud design. Implementation stage is shown in Figure 4.

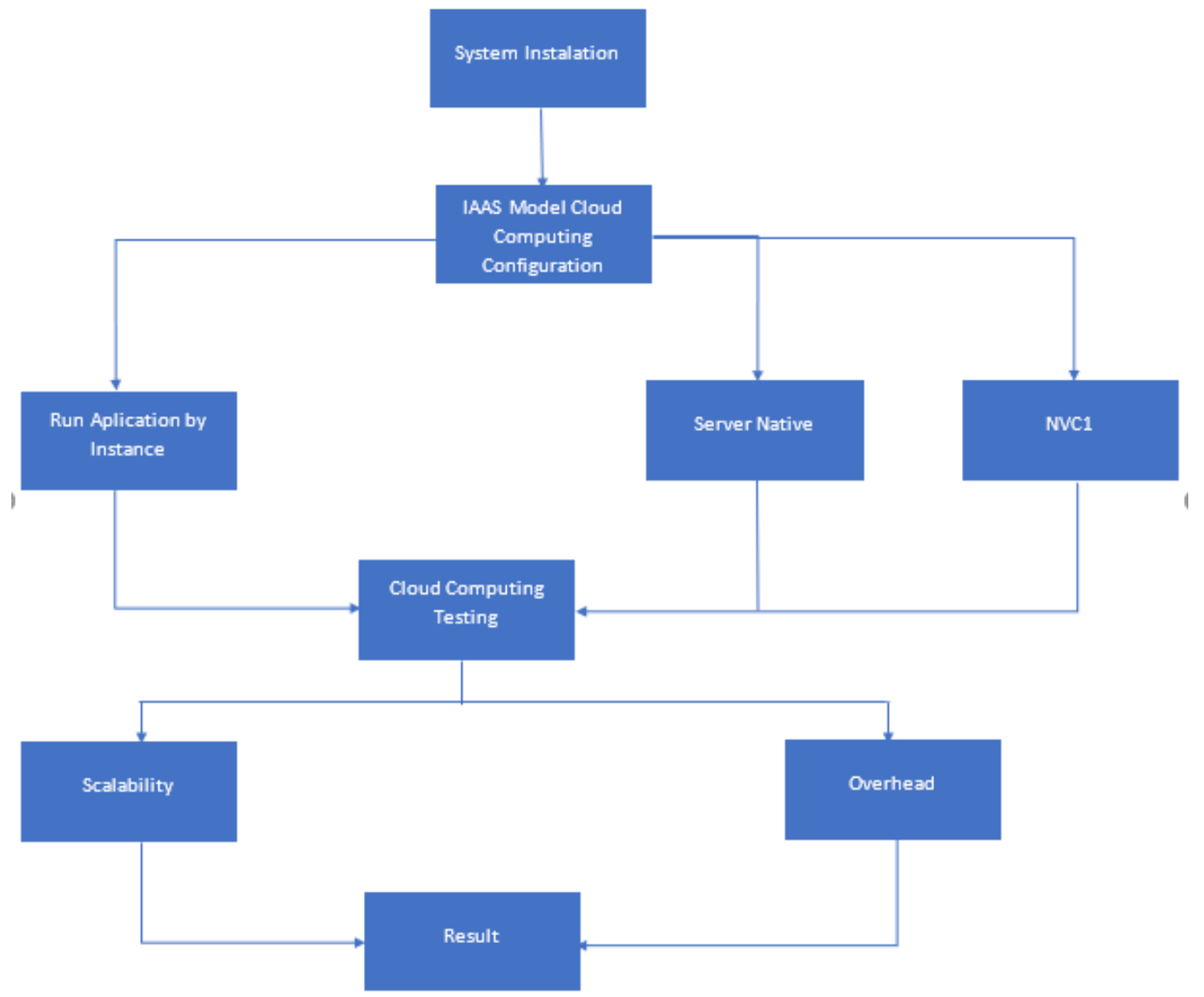

Figure 4. Implementation stage

The scenario for developing openstack private cloud computing to determine server scalability and resource overhead is shown in Figure 5.

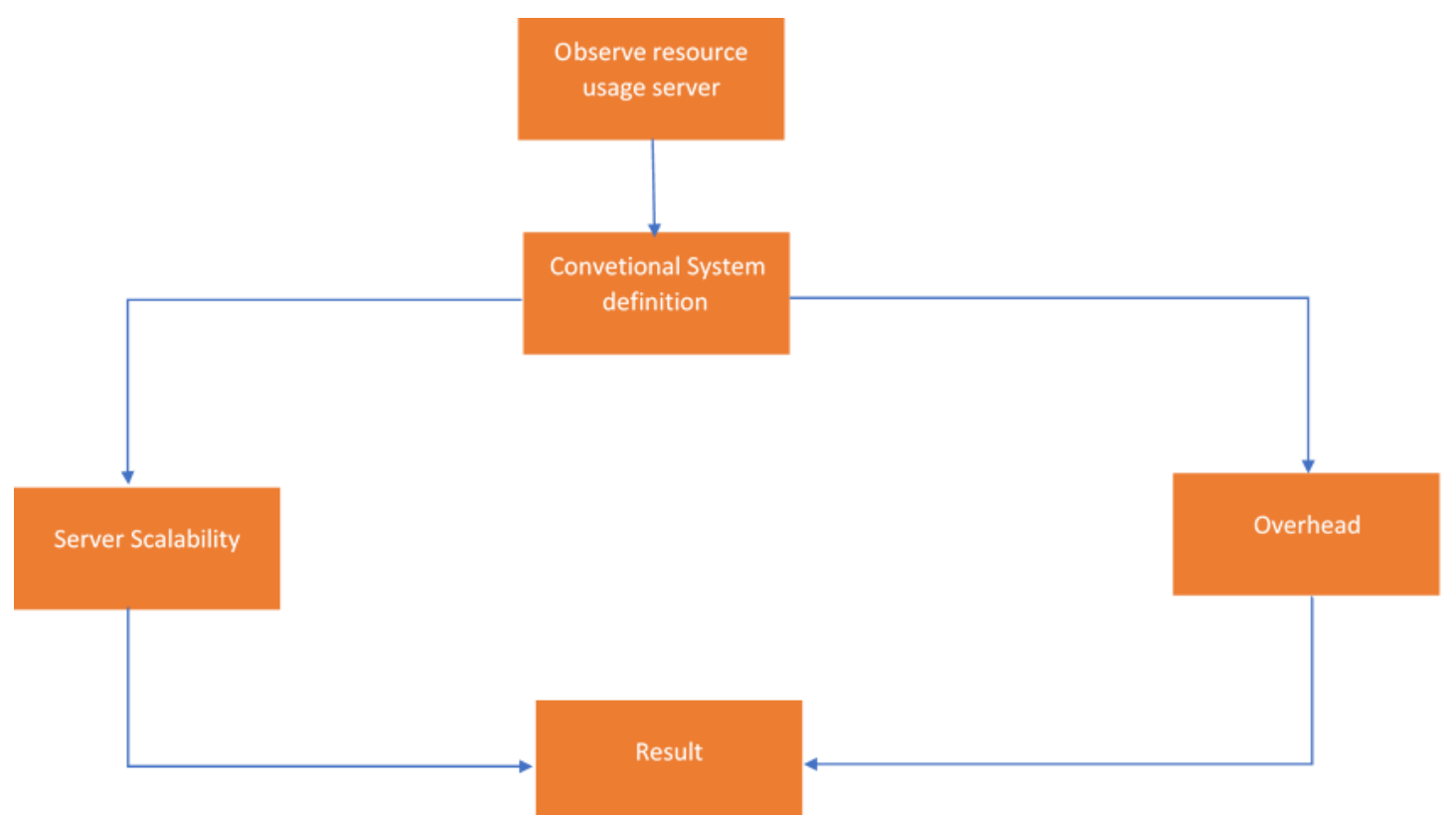

Figure 5. Development Scenario

Suriansyah, et. al. (Compute functional analysis leveraging the IAAS private cloud computing service model in packstack development) 


\section{E. Monitoring Phase}

The monitoring stage was the stage to test the implemented private cloud whether it was feasible or not to be used as a private cloud server infrastructure. This was done by horizon access, keypair creation, security group creation, flavor creation, instance creation, and instance access.

\section{F. Management Stage}

This stage was conducted more on maintenance and maintenance activities of the system so that the infrastructure system that was built could be used properly and lasted for a long time. This stage determined which users could access and manage the infrastructure system.

\section{G. Hardware Requirements}

Table 2 is hardware requirements for private cloud computing research.

Table 2. Server Specification

\begin{tabular}{|c|l|l|l|}
\hline No & Hardware & Notes & Node \\
\hline 1 & Intel (R) Xeon (R) CPU E3-1220 v6 @ 3 GHz & $\begin{array}{l}\text { Server 1; RAM 16 GB, 4 cores CPU, Hardisk SATA 2 } \\
\text { TB }\end{array}$ & Controller \\
\hline 2 & $\begin{array}{l}\text { Intel (R) Xeon (R) CPU E5-2650 v3 @ 2.3 } \\
\text { GHz }\end{array}$ & $\begin{array}{l}\text { Server 2; RAM 128 GB, 40 cores CPU, Hardisk 148 } \\
\text { GB SSD }\end{array}$ & Compute 1 \\
\hline 3 & $\begin{array}{l}\text { Intel (R) Xeon (R) CPU E3-1220 v3 @ 3.1 } \\
\text { GHz }\end{array}$ & $\begin{array}{l}\text { Server 3; RAM 4 GB, 4 cores CPU, Hardisk SATA 1 } \\
\text { TB }\end{array}$ & Compute 2 \\
\hline 4 & Lan card interface & Each node has an internal network and an external network \\
\hline
\end{tabular}

\section{Results and Discussion}

The result of the development of packstacks for the analysis of compute functions with the IAAS service model on private cloud computing and cloud computing was developed using openstack single controller and multi compute. Login Page openstack is shown in Figure 6.

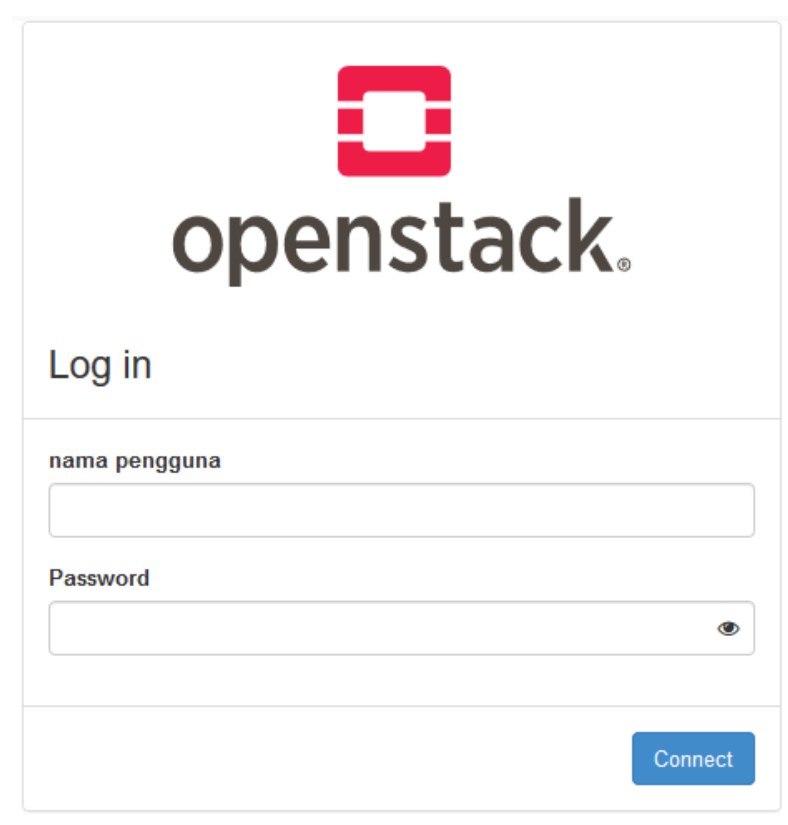

Figure 6. Login Page Display

Host group, this menu contained information of the number of hosts in private cloud computing, namely Host Controller and Compute. Figure 7 shows that there are one Host Node Controller and two Host Compute Nodes.

Suriansyah, $\boldsymbol{e t}$. al. (Compute functional analysis leveraging the IAAS private cloud computing service model in packstack development) 


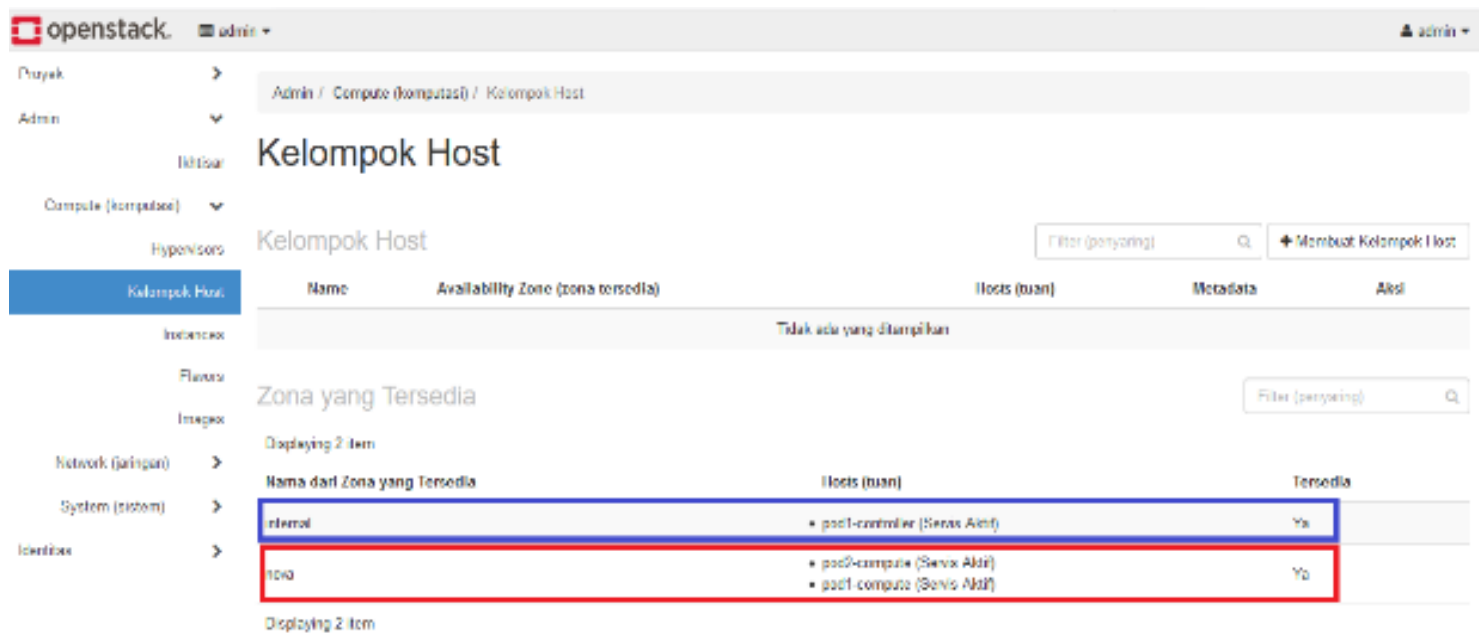

Figure 7. Host Group Display

The Hypervisor menu contained information about the resources available in private cloud computing. The information data were CPU, RAM memory, local disk usage shown in Figure 8.

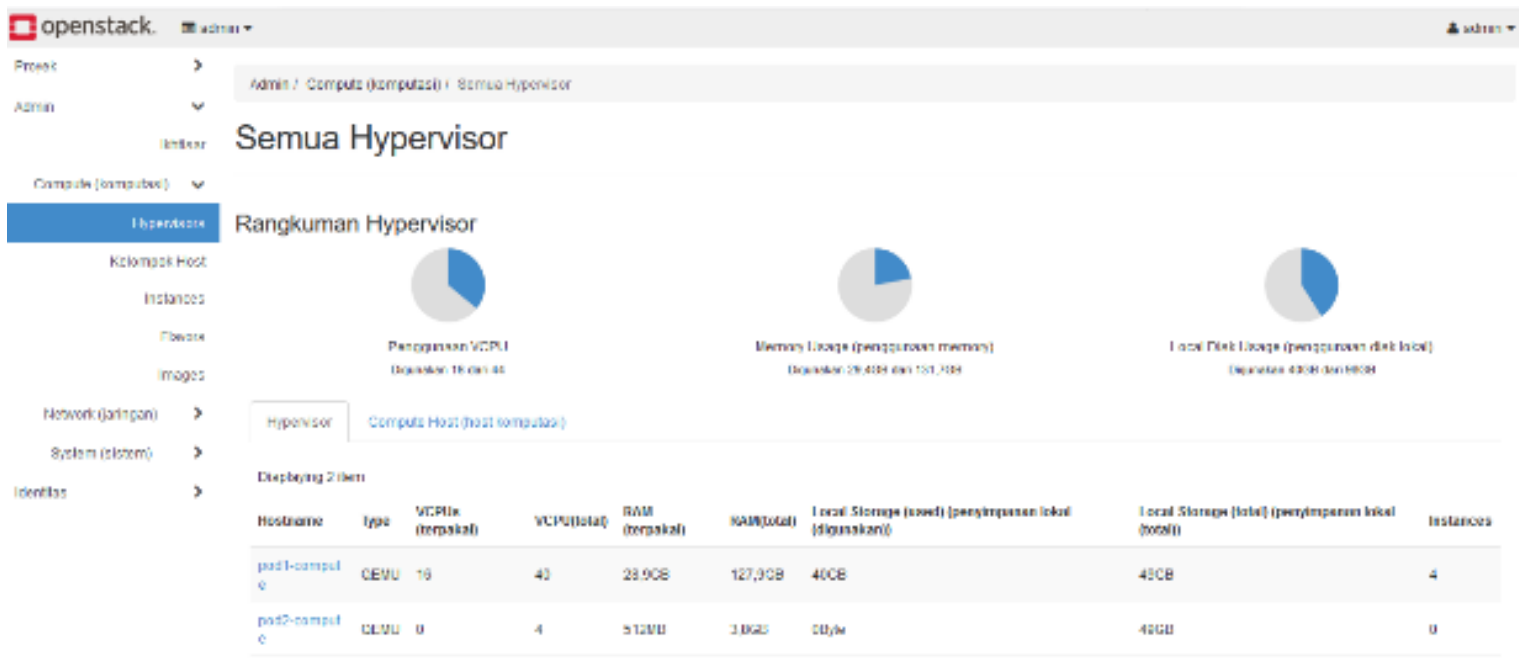

Figure 8. Hypervisor Menu Display

To measure the scalability of cloud server services, an upgrade test of cloud server specifications was carried out in a running state. Figure 9 show tests carried out using PRTG tools obtained a downtime value of 16 seconds from 20:24:08 WIB to 20:24:24 WIB. Monitoring Server Cloud Native Server shown in Figure 10.

\begin{tabular}{lllllll}
0 08/05/2019 20.24.24 & Error & Error & Error & Error & Error & $100 \%$ \\
\hline $08 / 05 / 201920.24 .08$ & Error & Error & Error & Error & Error & $100 \%$ \\
\hline
\end{tabular}

Figure 9. Downtime Upgrade Server

Suriansyah, et. al. (Compute functional analysis leveraging the IAAS private cloud computing service model in packstack development) 


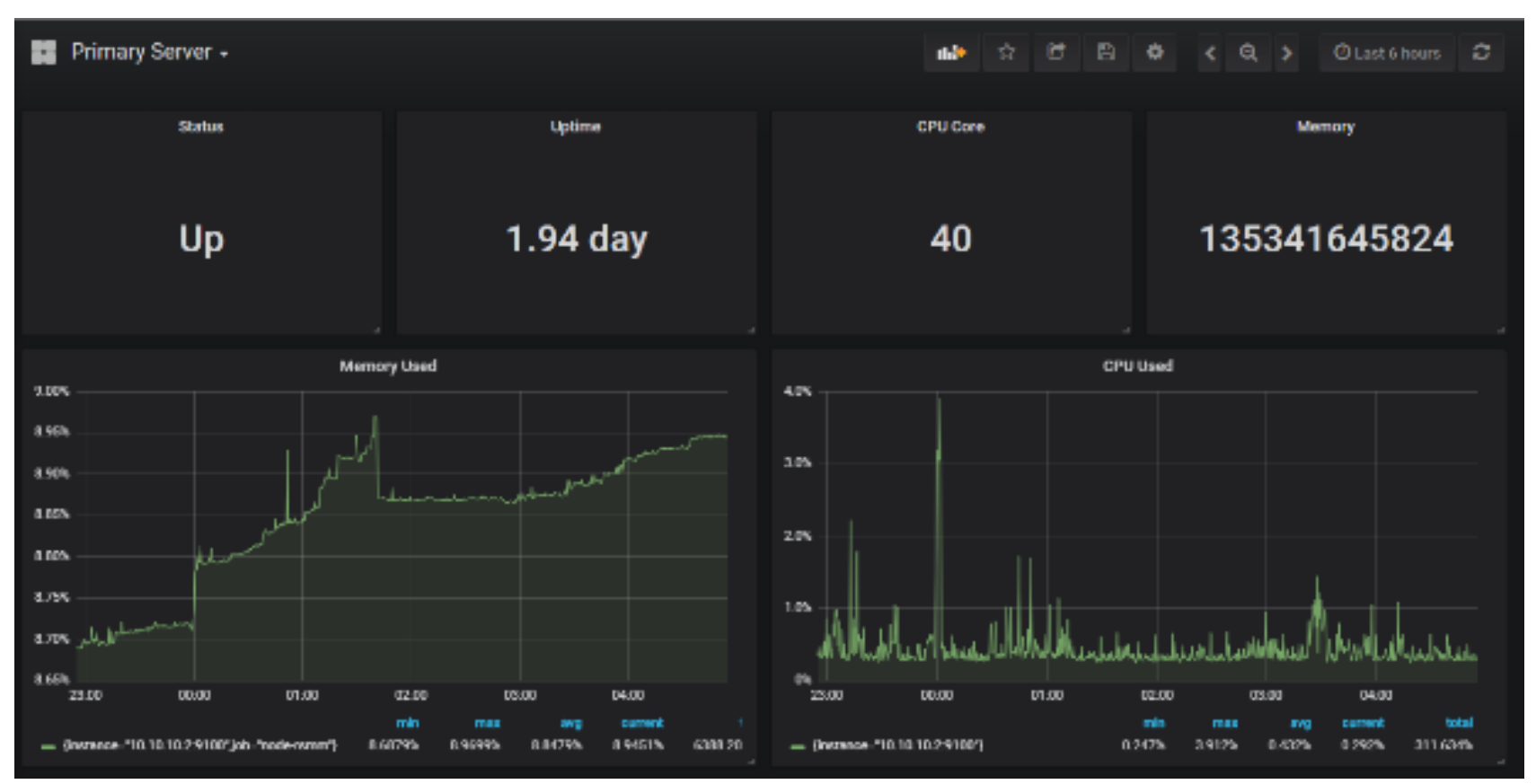

Figure 10. Monitoring Server Cloud Native Server

Based on the results of the cloud server service overhead test, the use of the resource looked quite stable. Even though when viewed in more detail there were some fluctuations when the application on the NVC1 cloud server was tested running. Monitoring Server Cloud NVC1 shown in Figure 11.

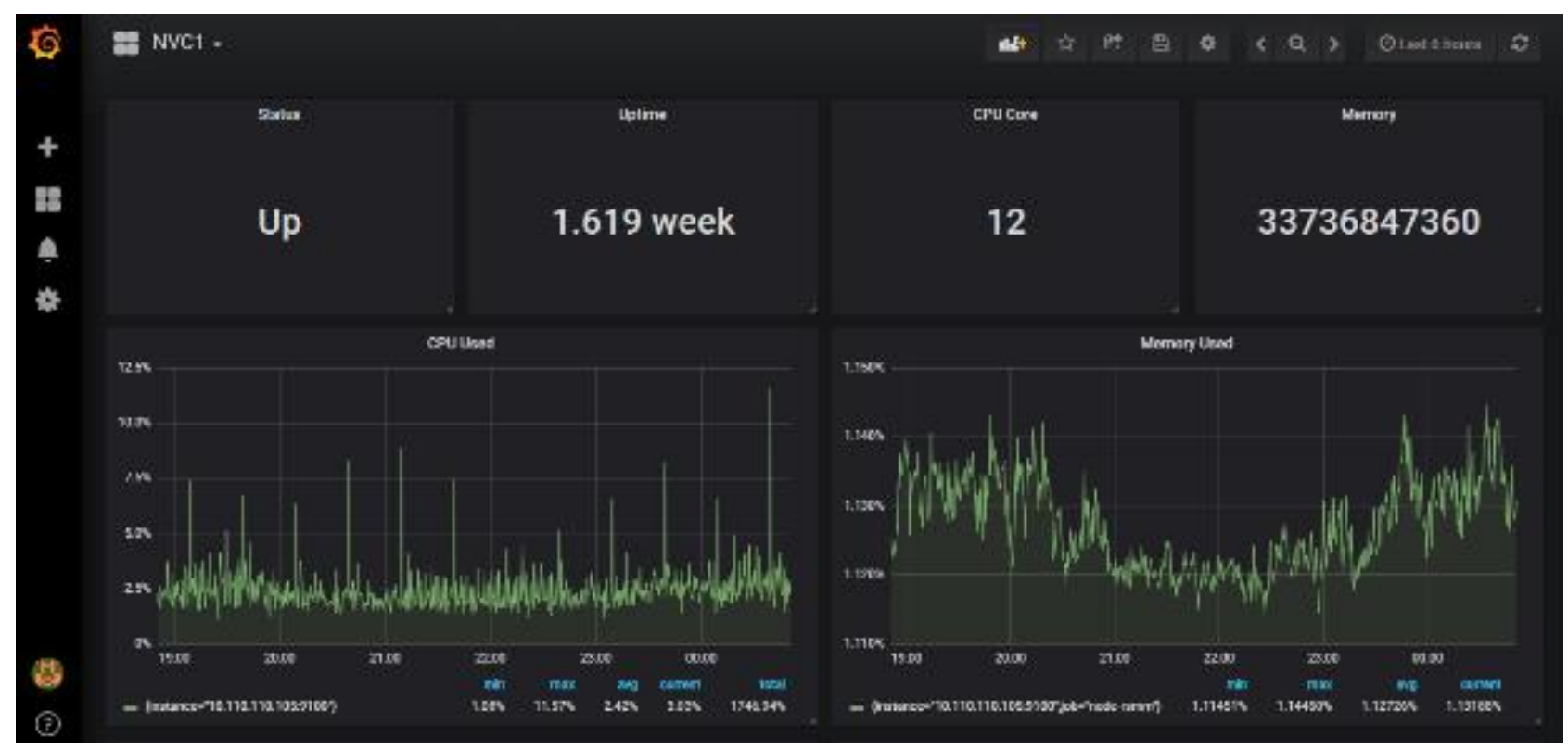

Figure 11. Monitoring Server Cloud NVC1

Furthermore, the test that was conducted resulted in the memory usage and CPU resource usage. These results can be seen in Figure 12 and Figure 13.

Suriansyah, et. al. (Compute functional analysis leveraging the IAAS private cloud computing service model in packstack development) 


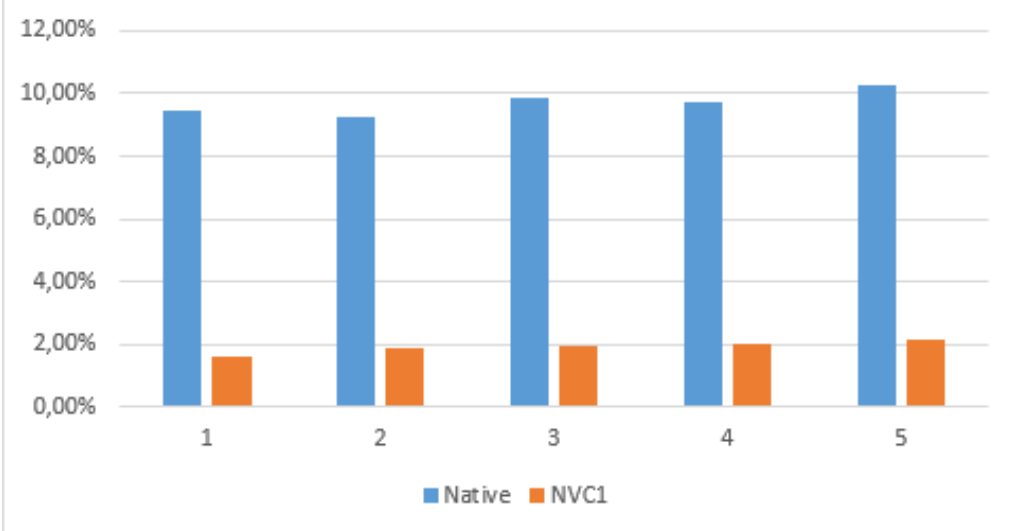

Figure 12. Memory Utility Usage

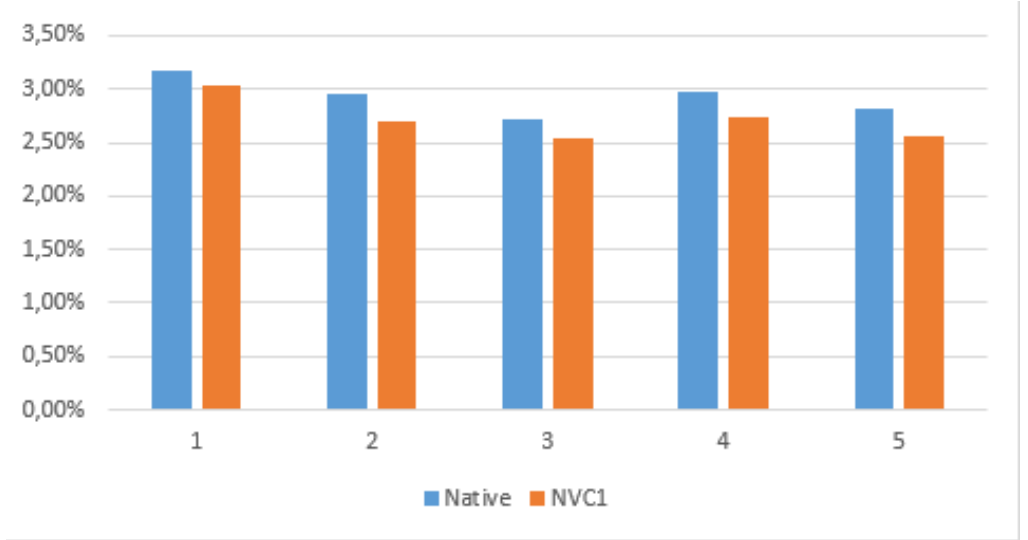

Figure 13. CPU Utility Usage

To measure cloud server overhead in this study, a testing was run for time calculations in each cloud server. In this respect, the time refers to the execution time. The tests generated optimization results shown in Table 3.

Table 3. Overhead

\begin{tabular}{|l|l|l|l|}
\hline No. & Parameter & Native & Cloud \\
\hline 1 & Overhead & 191 seconds & 185 seconds \\
\hline 2 & Reboot & 186 seconds & 105 seconds \\
\hline 3 & Startup & 144 seconds & 84 seconds \\
\hline 4 & Utilitas $C P U$ & $2,93 \%$ & $2,72 \%$ \\
\hline 5 & Utilitas Memory & $9,72 \%$ & $1,92 \%$ \\
\hline
\end{tabular}

\section{Conclusion}

Some conclusions that can be obtained after testing the scalability and overhead of private cloud computing using openstack are as follows 1) packstack has been successfully developed for the analysis of compute functions. Based on scalability testing, server upgrades could be performed in a running condition with a downtime of 16 seconds. 2) In measuring the overhead value in private cloud computing using OpenStack, we obtained the following optimization parameter values overhead with an optimization value of 6 seconds, reboot with an optimization value of 81 seconds, startup with an optimization value of 60 seconds, CPU utility with an optimization value of $0.21 \%$, memory utility with an optimization value of $7.80 \%$. There are a few suggestions for further research the development of private cloud computing could only support single controller and multi compute. It is hoped that further research can develop multi controllers and multi compute packstacks. It is hoped that further research can apply automation technology such as Ansible or Terraform for server administration efficiency using private cloud computing and integration with container technologies such as kubernetes cluster.

\section{Reference}

[1] T. Ananda, Rusmani, and A. Mulyana, "Design and realization of a grid computing system on infrastructure as a service using the Openstack cloud platform," in e-Proceeding of Engineering, 2016, pp. 743-748.

[2] M. Fauzan, A. Fiade, and F. Eka, "Analisis dan perancangan infrastruktur private cloud dengan Openstack," [Analysis and design of private cloud infrastructure with Openstack] J. Pseudocode, vol. 4, no. 2, 2017.

Suriansyah, et. al. (Compute functional analysis leveraging the IAAS private cloud computing service model in packstack development) 
[3] T. S. Somasundaram and K. Govindarajan, "CLOUDRB: A framework for scheduling and managing HighPerformance Computing (HPC) applications in science cloud,” Futur. Genes. Comput. Syst., vol. 34, pp. 47-65, 2014.

[4] A. Singh and M. Hemalatha, "Cloud Computing for Academic Environment," Int. J. Inf. comm. Technol. Res., 2012.

[5] M. Abualkibash and K. Elleithy, "Cloud Computing: The Future of IT Industry,” Int. J. Comput. Networks Commun., vol. 3, no. 4, pp. 1-12, 2012.

[6] D. Ardagna, "Cloud and Multi-Cloud Computing: Current Challenges and Future Applications," in IEEE/ACM 7th International Workshop on Principles of Engineering Service-Oriented and Cloud Systems Cloud, 2015.

[7] M. S. Rumetna, "Pemanfaatan cloud computing pada dunia bisnis : studi literatur," [Utilizating cloud computing in the business world: a literature study] vol. 5, no. 3, pp. 305-314, 2018.

[8] D. Ardagna, G. Casale, M. Ciavotta, J. Perez, and W. Wang, "Quality-of-service in cloud computing: modeling techniques and their applications," J. Internet Serv. Appl., 2014.

[9] L. Youseff, M. Butrico, and D. Da Silva, “Toward a Unified Ontology," in 2008 Grid Computing Environments Workshop, 2008.

[10] W. Jiyi, L. Ping, X. Ge, Y. Wang, and J. Fu, "Cloud Storage as the Infrastructure of Cloud Computing," in 2010 International Conference on Intelligent Computing and Cognitive Informatics, 2010.

[11] J. Sharif, "Membangun Private Cloud Computing dan Analisa Terhadap Serangan DoS, Study Kasus SMKN 6 Jakarta," [Building Private Cloud Computing and Analysis of DoS Attacks: Case Study of SMKN 6 Jakarta] IncomTech, J. Telekomun dan Komput., vol. 6, no. 3, 2015.

[12] W. Arsa and M. Khabib, "Perancangan dan Analisis Kinerja Private Cloud Computing dengan Layanan Infrastructure-As-A-Service," [Private Cloud Computing Performance Design and Analysis with InfrastructureAs-A-Service Services] BIMIPA, vol. 24, no. 3, pp. 225-237, 2014.

[13]H. Triyanto, A. Negara, and M. A. Irwansyah, "Analisa Perbandingan Performa Openstack dan Apache Cloudstack dalam Model Cloud Computing Berbasis Infrastructure As a Service," [Comparative Analysis of Openstack and Apache Cloudstack Performance in a Cloud Computing Model Based on Infrastructure As a Service] J. Sist. and Teknol. Inf., vol. 8, no. 1, pp. 78-86, 2020.

[14]P. G. S. C. Nugraha, I. K. A. Mogi, and I. M. A. Setiawan, "Implementasi private cloud computing sebagai layanan infrastructure as a service (IAAS) menggunakan openstack," [Implementation of private cloud computing as a service infrastructure (IAAS) using openstack] J. Ilm. Komput. Univ. Udayana, vol. 8, no. 2, pp. 7-14, 2015.

[15] J. Heizer and B. Render, Operations Management, 10th Edition. New Jersey: Pearson Education, Inc., 2011.

Suriansyah, et. al. (Compute functional analysis leveraging the IAAS private cloud computing service model in packstack development) 